\title{
Dietary patterns and the risk of metabolic syndrome in Chinese adults: a population-based cross-sectional study
}

\author{
Zhi-Yong Wei ${ }^{1}$, Jun-Jie Liu ${ }^{2}$, Xue-Mei Zhan ${ }^{1}$, Hao-Miao Feng ${ }^{3}$ and Yuan-Yuan Zhang ${ }^{4, *}$ \\ 'Department of Pathology, Linyi People's Hospital, Linyi, Shandong, People's Republic of China: ${ }^{2}$ Department of \\ Pathology, Chinese Medicine Hospital in Linyi City, Linyi, Shandong, People's Republic of China: ${ }^{3}$ Department of \\ General Surgery, Linyi People's Hospital, Linyi, Shandong, People's Republic of China: ${ }^{4}$ Department of Endocrinology, \\ Linyi People's Hospital, Jiefang Road No. 27, Lanshan District, Linyi 276003, Shandong, People's Republic of China
}

Submitted 16 August 2017: Final revision received 26 February 2018: Accepted 28 March 2018; First published online 2 May 2018

\begin{abstract}
Objective: Data on dietary patterns in relation to the risk of metabolic syndrome (MetS) in a middle-aged Chinese population are sparse. The present study was performed to determine the major dietary patterns among a population aged 45-59 years and to evaluate their associations with MetS risk in China.

Design: Cross-sectional examination of the association between dietary patterns and MetS. Face-to-face interviews were used to assess dietary intake using a validated semi-quantitative FFQ. OR and 95\% CI for MetS were calculated across quartiles of dietary pattern scores using multivariate logistic regression analysis models.

Setting: City of Linyi, Shandong Province, China.

Subjects: Adults ( $n$ 1918) aged 45-59 years.

Results: Three major dietary patterns were identified: traditional Chinese, animal food and high-energy. After adjustment for potential confounders, individuals in the highest quartile of the traditional Chinese pattern had a reduced risk of MetS relative to the lowest quartile ( $\mathrm{OR}=0.72,95 \%$ CI $0.596,0.952 ; P<0.05)$. Compared with those in the lowest quartile, individuals in the highest quartile of the animal food pattern had a greater risk of MetS (OR $=1 \cdot 28$; 95\% CI 1.103 , 1.697; $P<0.05$ ). No significant association was observed between the high-energy pattern and risk of MetS.

Conclusions: These findings indicate that the traditional Chinese pattern was associated with a reduced risk, while the animal food pattern was associated with increased risk of MetS. Given the cross-sectional nature of our study, further prospective studies are warranted to confirm these findings.
\end{abstract}

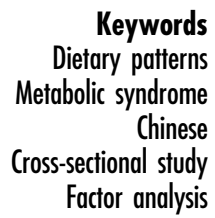

The metabolic syndrome (MetS) is a cluster of interrelated risk factors including hypertension, obesity, hyperglycaemia, hypertriacylglycerolaemia and low HDL-cholesterol ${ }^{(1)}$. A rapid increase in the prevalence of MetS from 24.9\% in 1998 to $37.0 \%$ in 2012 has been found in Korea, becoming a major health issue ${ }^{(2)}$. Besides, recent a cross-sectional study by Choi et al. reported that the prevalence of MetS was $11.4 \%$ in Korean women ${ }^{(3)}$. In China, parallel with the development of the economy, the prevalence of MetS has also increased considerably from $13.7 \%$ in $2000-2001$ to $27 \cdot 4 \%$ in $2009-2010^{(4)}$. It is well known that MetS is a multifactorial disorder that may be associated with some risk factors, such as alcohol consumption, high salt intake, genetic factors and dietary factors ${ }^{(5,6)}$.

An emerging body of evidence has shown that diet plays an important role in developing MetS. Over the past several decades, some epidemiological studies have examined the association of MetS with the intakes of specific food groups, individual foods and nutrients ${ }^{(7,8)}$. However, nutrients or foods are not consumed in isolation but in numerous different combinations. In this context, dietary pattern analysis, which reflects the complexity of dietary intake, has emerged as an alternative and complementary approach to reporting the association of diet with the risk of chronic diseases that considers the complexity of overall diet and facilitates nutritional recommendations ${ }^{(9)}$.

Until now, many studies have been performed to verify the associations between dietary patterns and the risk of MetS worldwide ${ }^{(4,10,11)}$. However, studies on the association between dietary pattern and the risk of MetS have reported inconsistent findings. Besides, to the best of our 
knowledge, data on dietary patterns in relation to the risk of MetS are sparse in China ${ }^{(10,12)}$, particularly among a middle-aged Chinese population. Therefore, the purpose of the present study was to identify the major dietary patterns existing in a Chinese population aged $45-59$ years and to evaluate their associations with the risk of MetS.

\section{Participants and methods}

\section{Study population}

During August 2014 to December 2016, the current crosssectional study was performed to collect data in a representative sample of Chinese adults aged 45-59 years selected by a multistage cluster random-sampling method. The participants were from Linyi, a prefecture-level city of Shandong Province, China, with a population of 11 million. The present study sample was taken from three areas (Lanshan, Luozhuang and Hedong) and nine counties (Lanling, Junan, Qishui, Tancheng, Mengyin, Pingyi, Feixian, Yinan and Linshu). We chose two residential villages or communities from each of these areas and counties, according to residents' health records. Each participant provided written informed consent prior to enrolment. A total of 2374 eligible participants were invited to attend health screening examinations at the Medical Center for Physical Examination, Linyi People's Hospital, where the participants were interviewed faceto-face by a trained interviewer using written questionnaires. First, 206 participants with a history of diabetes, CVD or stroke were excluded because of possible diseaserelated changes in diet. In addition, we also excluded the participants with missing information on dietary intake and anthropometric information, and who were taking medications that would affect serum lipoprotein concentrations, blood pressure and carbohydrate metabolism ( $n$ 250). Finally, a total of 1918 individuals (996 men and 922 women) remained for the present analysis of the associations between dietary patterns and MetS. The study protocol was approved by the Ethics Committee of Linyi People's Hospital.

\section{Assessment of dietary intake}

Face-to-face interviews were used to assess dietary intake using a validated semi-quantitative FFQ in which most foods consumed in Shandong Province were covered. The validity of the FFQ was evaluated by a pilot survey within a middle-aged Chinese population by comparison with three $24 \mathrm{~h}$ dietary recalls prior to the present study. The correlation coefficients between the FFQ and means from the $24 \mathrm{~h}$ dietary recalls ranged between 0.51 and 0.76 for major food groups. In brief, these data indicated that the FFQ provided reasonably valid measurements of dietary intakes. Participants were asked to report their frequency of consumption of a given serving of each food item during the previous year. Briefly, participants were asked to recall the frequency of consumption of each food item in the previous 12 months and the estimated portion size, using local weight units (e.g. 1 liang $=50 \mathrm{~g}$ ) or natural units (cups). For instance, the frequency response for food consumption included nine categories, as follows: never, less than once/month, 1-3 times/month, 1-2 times/week, 3-4 times/week, 5-6 times/week, 1 time/d, 2 times/d and 3 times/d; subsequently, individual food items were converted into a mean daily consumption. The 138 food items listed in the FFQ were divided into thirty food groups, each of which was based on the similarity of nutrients (Table 1).

\section{Identification of dietary patterns}

The 138 food items in the FFQ were aggregated into thirty predefined food groups based on similarity of type of food and nutrient composition. The Kaiser-Meyer-Olkin

Table 1 Food grouping used in the dietary pattern analyses

\begin{tabular}{|c|c|}
\hline Food group & Food item \\
\hline Refined grains & $\begin{array}{l}\text { Rice, porridge, rice in soup, noodles, } \\
\text { instant noodles, steamed bun, wonton, } \\
\text { dumplings, white breads, toasted bread }\end{array}$ \\
\hline Whole grains & Corn, sorghum, millet, oats \\
\hline Tubers & Sweet potato, potato, taro \\
\hline Vegetables & $\begin{array}{l}\text { Wild vegetables, green vegetables, } \\
\text { spinach, green peppers, tomato, Chinese } \\
\text { cabbage, radish, cucumber, aubergine }\end{array}$ \\
\hline Fruit & $\begin{array}{l}\text { Apple, pears, peaches, apricots, cherries, } \\
\text { grapes, bananas, cantaloupe, } \\
\text { watermelon, oranges, grapefruit, kiwi, } \\
\text { strawberries, etc. }\end{array}$ \\
\hline Pickled vegetables & Salted vegetables, Chinese sauerkraut \\
\hline Mushrooms & Mushroom, shiitakes, enoki \\
\hline Red meat & Pork, mutton, beef \\
\hline Poultry and organs & Chicken, duck, liver, animal blood \\
\hline $\begin{array}{l}\text { Processed and cooked } \\
\text { meat }\end{array}$ & Ham and sausage, sauced pork, roast duck \\
\hline Fish and shrimp & Fish, s \\
\hline Eggs & Duck eggs, chicken eggs \\
\hline Seafood & $\begin{array}{l}\text { Sea fish, shrimp, crab, squid, jellyfish, } \\
\text { shellfish }\end{array}$ \\
\hline Bacon and salted fish & Salted meat and duck, salted fish \\
\hline $\begin{array}{l}\text { Salted and preserved } \\
\text { eggs }\end{array}$ & $\begin{array}{l}\text { Salted duck and chicken eggs, preserved } \\
\text { eggs }\end{array}$ \\
\hline Milk & Liquid milk, milk powder, yoghurt \\
\hline Cheese & Cheese \\
\hline $\begin{array}{l}\text { Soyabean and its } \\
\text { products }\end{array}$ & Tofu, dried bean curd, soya milk \\
\hline Miscellaneous beans & Mung beans, red beans, hemp beans \\
\hline Fats & Lard, butter \\
\hline Vegetable oil & Soyabean oil, tea oil, rapeseed oil, olive oil \\
\hline Fast foods & $\begin{array}{l}\text { KFC, McDonald's, fried dough sticks and } \\
\text { twists, fried cakes, pizza }\end{array}$ \\
\hline Nuts & Walnut, peanuts, almonds, melon seeds \\
\hline Snacks & $\begin{array}{l}\text { Cookies, sachima, bread, cake, ice cream, } \\
\text { candy, sweets, potato chips, shrimp roll, } \\
\text { popcorn }\end{array}$ \\
\hline Chocolates & Chocolates \\
\hline Honey & Honey, hydromel \\
\hline Drinks & $\begin{array}{l}\text { Coca-Cola, Sprite, fruit and vegetable } \\
\text { drink, fruits juice }\end{array}$ \\
\hline Alcoholic beverages & Beer, fruit wine, grape wine \\
\hline $\begin{array}{l}\text { Tea } \\
\text { Coffee }\end{array}$ & $\begin{array}{l}\text { Tea, scented tea, Wong Lo Kat } \\
\text { Coffee }\end{array}$ \\
\hline
\end{tabular}


measure of sample adequacy and the Bartlett test of sphericity were used to assess data adequacy for factor analysis. Factor analysis (principal component) was used to derive the major dietary patterns in the population based on the frequency of consumption of the thirty predefined food groups. The factors were rotated by an orthogonal transformation (varimax rotation) to achieve simpler structure with greater interpretability using the statistical software package IBM SPSS Statistics version 20.0. The number of retained factors was determined according to eigenvalue, scree plot and the interpretability of the factors ${ }^{(13)}$. After evaluating the eigenvalues, scree plot and factor interpretability, factors with an eigenvalue of $\geq 1.5$ were retained. In the present study, individual food items with an absolute factor loading of $\geq 0.4$ were considered to contribute significantly to the pattern. Factor scores were categorized into quartiles (Q1 represented a low intake of this pattern; Q4 represented a high intake of this pattern).

\section{Assessment of blood pressure}

For blood pressure measurement, the participant was first asked to rest for $10 \mathrm{~min}$. Then, a trained nurse measured the participant's blood pressure three times using a standard mercury sphygmomanometer with the participant in the sitting position. Thereafter, the mean of three measurements was considered as the participant's blood pressure.

\section{Assessment of biomarkers}

Blood samples were obtained after $12 \mathrm{~h}$ of fasting overnight. After blood was collected, the sample was allowed to clot at room temperature for $1-3 \mathrm{~h}$ and the serum was separated by centrifugation for $15 \mathrm{~min}$ at $3000 \mathrm{rpm}$. Then serum samples were analysed in the Medical Center for Physical Examination of Linyi People's Hospital for fasting plasma glucose, total cholesterol, TAG, HDL-cholesterol, LDL-cholesterol, uric acid, alanine aminotransferase and aspartate aminotransferase using a Hitachi 7180 auto-analyser (Hitachi, Tokyo, Japan).

\section{Assessment of anthropometric measurements}

Each participant's weight in light clothes and without shoes was measured using a digital scale to the nearest $100 \mathrm{~g}$. Height was measured to the nearest $0.1 \mathrm{~cm}$ with the participant standing without shoes. BMI was calculated as weight (in kilograms) divided by the square of height (in metres). Waist circumference was measured halfway between the lower rib edge and the upper iliac crest by means of a metric measure with an accuracy of $1 \mathrm{~mm}^{(14)}$. All measurements were performed by nurses trained to use standardized procedures.

\section{Assessment of other variables}

Data on participants' physical activity levels were obtained by using the International Physical Activity Questionnaire $(\text { IPAQ })^{(15)}$. The physical activity levels were expressed as metabolic equivalents of task (MET) hours per week, in which activities with different MET levels were ranged on a scale from sleep/rest (0.9 MET) to high-intensity physical activities ( $>6$ MET). We calculated the physical activity level by multiplying the MET level of each reported activity by its duration (hours) in a week. The values obtained for various reported activities were added together and expressed as MET-h/week, which was then grouped into light, moderate and heavy ${ }^{(14)}$. Additional information such as smoking habits (never, current, former smoker), educational level ( $<$ high school, high school, $>$ high school) was obtained with questionnaires. Besides, total energy intake was estimated through the FFQ, expressed in kilocalories per day and categorized according to quartile.

\section{Definition of metabolic syndrome}

According to the 2009 International Diabetes Federation criteria $^{(16)}$ and the Chinese-specific abdominal obesity standard in adults ${ }^{(12)}$, participants who met at least three of the following conditions were defined as having MetS: (i) high TAG (i.e. serum TAG $\geq 1.7 \mathrm{mmol} / \mathrm{l}$; (ii) low HDL-cholesterol (i.e. serum HDL-cholesterol $<1.0 \mathrm{mmol} / 1$ for males and $<1.3 \mathrm{mmol} / \mathrm{l}$ for females); (iii) hypertension (i.e. systolic blood pressure $\geq 130 \mathrm{mmHg}$ and/or diastolic blood pressure $\geq 85 \mathrm{mmHg}$ or a history of hypertension); (iv) hyperglycaemia (i.e. fasting plasma glucose $\geq 5.6 \mathrm{mmol} / \mathrm{l}$ or a diagnosis of type 2 diabetes mellitus); and (v) central obesity (i.e. waist circumference $\geq 90 \mathrm{~cm}$ for males or $\geq 85 \mathrm{~cm}$ for females).

\section{Statistical analyses}

The general characteristics of study participants across quartile categories of the dietary pattern scores were calculated. Data are presented as mean values and standard deviations for continuous variables, and numbers and percentages for categorical variables. One-way ANOVA with Tukey's post hoc comparison was performed to evaluate significant differences in general characteristics (e.g. gender, age, economic income, education level and physical activity) across quartile categories of the dietary pattern scores. Besides, we used the $\chi^{2}$ test to assess the difference in categorical variables. After adjustment for potential confounders, OR and 95\% CI for MetS were calculated across the quartiles of dietary pattern scores using multivariate logistic regression analysis models. Model 1 was adjusted for sex and age; Model 2 was further adjusted for education level ( $<$ high school, high school, $>$ high school), physical activity level (light, moderate, heavy), smoking status (never, current, former); Model 3 was additionally adjusted for total energy intake. All analyses were conducted using IBM SPSS Statistics version 20.0 and a two-tailed $P<0.05$ was considered statistically significant.

\section{Results}

Overall prevalence of MetS in our study population was $23.6 \%$, with $13.2 \%$ among males and $10.4 \%$ among 
Table 2 General and clinical characteristics of middle-aged adults $(n$ 1918) with and without metabolic syndrome (MetS) in the city of Linyi, Shandong Province, China, August 2014-December 2016

\begin{tabular}{|c|c|c|c|c|c|}
\hline \multirow[b]{2}{*}{ Variable } & \multicolumn{2}{|c|}{$\begin{array}{l}\text { Participants with MetS } \\
\text { ( } n \text { 453) }\end{array}$} & \multicolumn{2}{|c|}{$\begin{array}{l}\text { Participants without MetS } \\
\text { (n 1465) }\end{array}$} & \multirow[b]{2}{*}{ Significance } \\
\hline & Mean or $n$ & SD or $\%$ & Mean or $n$ & SD or $\%$ & \\
\hline Age (years) & 54.82 & 9.63 & 51.48 & 9.56 & $P<0.001$ \\
\hline \multicolumn{6}{|l|}{ Gender } \\
\hline Male & 253 & $55 \cdot 8$ & 743 & $50 \cdot 7$ & $x^{2}=3.652$ \\
\hline Female & 200 & $44 \cdot 2$ & 722 & $49 \cdot 3$ & $P=0.056$ \\
\hline \multicolumn{6}{|l|}{ Smoking status } \\
\hline Never & 342 & 75.5 & 1154 & $78 \cdot 8$ & $x^{2}=3.481$ \\
\hline Former & 27 & 2.9 & 50 & 3.4 & $P=0.175$ \\
\hline Current & 98 & $21 \cdot 6$ & 261 & $17 \cdot 8$ & \\
\hline \multicolumn{6}{|l|}{ Education } \\
\hline$<$ High school & 44 & $9 \cdot 8$ & 264 & $18 \cdot 0$ & $x^{2}=23.727$ \\
\hline High school & 369 & 81.4 & 1125 & $76 \cdot 8$ & $\hat{P}<0.001$ \\
\hline$>$ High school & 40 & 8.8 & 76 & $5 \cdot 2$ & \\
\hline \multicolumn{6}{|c|}{ Monthly income per person } \\
\hline$\leq 2500 \mathrm{RMB}$ & 202 & $44 \cdot 6$ & 541 & 36.9 & $x^{2}=17.475$ \\
\hline $2500-4000$ RMB & 218 & $48 \cdot 2$ & 721 & $49 \cdot 2$ & $P<0.001$ \\
\hline$>4000 \mathrm{RMB}$ & 33 & $7 \cdot 2$ & 203 & 13.9 & \\
\hline \multicolumn{6}{|l|}{ Obese } \\
\hline Yes & 61 & 13.5 & 79 & 5.4 & $x^{2}=33.329$ \\
\hline No & 392 & $86 \cdot 5$ & 1386 & $94 \cdot 6$ & $P<0.001$ \\
\hline \multicolumn{6}{|l|}{ Hypertension } \\
\hline Yes & 120 & $26 \cdot 5$ & 321 & 21.9 & $x^{2}=4.097$ \\
\hline No & 333 & 73.5 & 1144 & $78 \cdot 1$ & $P<0.05$ \\
\hline
\end{tabular}

Continuous variables are presented as mean and standard deviation; categorical variables as number and percentage.

${ }^{*} P$ values are calculated using ANOVA for continuous variables; the $x^{2}$ test for categorical variables.

females. General and clinical characteristics of participants with and without MetS are shown in Table 2. There were significant differences between participants with and without MetS according to age, education, economic income and prevalence of obesity and hypertension $(P<0.05)$.

Both the Kaiser-Meyer-Olkin index (0.703) and Bartlett's test $(P<0 \cdot 001)$ indicated that the correlation among the variables was sufficiently strong for a factor analysis $^{(14)}$. We identified three major dietary patterns by using factor analysis: the traditional Chinese dietary pattern (high in whole grains, tubers, vegetables, fruit, pickled vegetables, mushrooms, bacon and salted fish, salted and preserved eggs, soyabean and its products, miscellaneous beans, vegetable oil and tea), the animal food dietary pattern (high in red meats, poultry and organs, processed and cooked meat, fish and shrimp, eggs, seafood, alcoholic beverages and coffee) and the high-energy dietary pattern (high in refined grains, milk, cheese, fats, fast foods, nuts, snacks, chocolates, honey and drinks), which accounted $10 \cdot 3,7.5$ and $5.2 \%$ of the dietary intake variance, respectively. The factor loading matrices for these dietary patterns are shown in Table 3.

General characteristics of study participants across quartiles of the major dietary pattern scores are presented in Table 4. Compared with participants in the lowest quartile, those in the highest quartile of the traditional Chinese dietary pattern were more likely to be female, older, non-smokers, have a lower prevalence of obesity, hypertension and MetS, with a lower BMI, waist circumference and waist-to-hip ratio, and higher income. Moreover, in comparison with the participants from the lowest quartile of the animal food dietary pattern, those in the highest quartile were more likely to be younger, male, smokers, have a higher prevalence of obesity, hypertension and MetS, with a higher BMI and waist circumference. Similarly, participants who belonged to the highest quartile of the high-energy pattern were more likely to be younger, male, smokers, with a higher education level and prevalence of obesity than those in the lowest quartile.

OR for MetS across quartile categories of dietary pattern scores are shown in Table 5. After adjustment for several confounding factors, participants in the highest quartile of the traditional Chinese dietary pattern score had lower odds of MetS (OR $=0.72,95 \%$ CI $0.596,0.952, P<0.05$ ) than those in the lowest quartile, whereas those in the highest quartile of the animal food dietary pattern score had greater odds of MetS (OR =1.28, $95 \%$ CI 1.103, 1.697, $P<0.05)$ than did those in the lowest quartile. However, no statistically significant association was observed between the high-energy dietary pattern and MetS.

\section{Discussion}

Overall prevalence of MetS in our study population was $23 \cdot 6 \%$, with $13 \cdot 2 \%$ among males and $10 \cdot 4 \%$ among females. As stated in above, three major dietary patterns were identified in the present study population: the traditional Chinese, the animal food and the high-energy dietary 
Table 3 Factor loading matrix for the three dietary patterns ${ }^{*}$ found among middle-aged adults ( $n$ 1918) in the city of Linyi, Shandong Province, China, August 2014-December 2016

\begin{tabular}{|c|c|c|c|}
\hline \multirow[b]{2}{*}{ Food group } & \multicolumn{3}{|c|}{ Dietary pattern } \\
\hline & $\begin{array}{l}\text { Traditional } \\
\text { Chinese }\end{array}$ & $\begin{array}{l}\text { Animal } \\
\text { food }\end{array}$ & $\begin{array}{l}\text { High- } \\
\text { energy }\end{array}$ \\
\hline Refined grains & - & - & 0.411 \\
\hline Whole grains & 0.534 & - & - \\
\hline Tubers & 0.471 & - & - \\
\hline Vegetables & 0.638 & - & - \\
\hline Fruit & 0.462 & - & - \\
\hline Pickled vegetables & 0.509 & - & - \\
\hline Mushrooms & 0.664 & - & - \\
\hline Red meat & - & 0.563 & - \\
\hline Poultry and organs & - & 0.502 & - \\
\hline Processed and cooked meat & - & 0.520 & - \\
\hline Fish and shrimp & - & 0.486 & - \\
\hline Eggs & - & 0.346 & - \\
\hline Seafood & - & 0.417 & - \\
\hline Bacon and salted fish & 0.529 & - & - \\
\hline Salted and preserved eggs & 0.414 & - & - \\
\hline Milk & - & - & 0.360 \\
\hline Cheese & - & - & 0.315 \\
\hline Soyabean and its products & 0.400 & - & - \\
\hline Miscellaneous bean & 0.414 & - & - \\
\hline Fats & - & - & 0.447 \\
\hline Vegetable oil & 0.392 & - & - \\
\hline Fast foods & - & - & 0.407 \\
\hline Nuts & - & - & 0.303 \\
\hline Snacks & - & - & 0.517 \\
\hline Chocolates & - & - & 0.435 \\
\hline Honey & - & - & 0.595 \\
\hline Drinks & - & - & 0.472 \\
\hline Alcoholic beverages & - & 0.301 & - \\
\hline Tea & 0.357 & - & - \\
\hline Coffee & - & 0.390 & - \\
\hline $\begin{array}{l}\text { Variance of intake } \\
\text { explained (\%) }\end{array}$ & $10 \cdot 3$ & $7 \cdot 5$ & $5 \cdot 2$ \\
\hline
\end{tabular}

*Absolute values $<0.4$ were excluded for simplicity.

patterns. The results indicated that the animal food pattern is associated with an increased risk, whereas the traditional Chinese pattern is associated with a decreased risk of MetS. Besides, no significant association was observed between the high-energy pattern and risk of MetS. To the best of our knowledge, the present study is the first among a middle-aged Chinese population to comprehensively evaluate the associations between major dietary patterns and the risk of MetS.

The traditional Chinese pattern identified in our analyses was associated with a significantly lower prevalence of MetS. Our findings are in line with previous studies ${ }^{(17)}$ which reported the favourable effect of the healthy dietary pattern on the prevention of MetS. The inverse association between the traditional Chinese pattern and risk of MetS could be attributed to this pattern's healthy constituents (e.g. whole grains, fruits and vegetables). Higher intakes of whole grains, vegetables and fruits may increase the amount of dietary fibre. A number of studies in recent years have found that dietary fibre is inversely associated with insulin resistance, an important risk factor for MetS ${ }^{(18)}$. Moreover, most foods (e.g. whole grains, tubers, vegetables, fruits and beans) in the traditional Chinese dietary pattern have a low glycaemic load, which has been documented to be associated with reduced risk of insulin resistance ${ }^{(19)}$. Furthermore, high intake of fruits and vegetables reducing the risk of MetS may be the result of lower C-reactive protein concentrations $^{(20)}$. Previous studies have shown that C-reactive protein concentrations are significantly associated with the risk of $\mathrm{MetS}^{(21)}$. The final possible mechanism for the protective effect of this pattern against MetS is that its constituents are good sources of antioxidants. Previous studies have indicated that antioxidants such as vitamin C, vitamin $\mathrm{E}$ and carotenoids that are abundant in fruits and vegetables can help to prevent oxidative stress, which is involved in the progression of $\mathrm{MetS}^{(22)}$.

In the present study, we found a positive association between the animal food pattern and risk of MetS. This finding is consistent with a previous study which indicated that the Western dietary pattern is associated with an increased risk of $\mathrm{MetS}^{(23)}$. Besides, a cross-sectional study performed in South Korea also demonstrated that the meat dietary pattern was significantly associated with increased MetS risk ${ }^{(24)}$. There are several possible explanations for the positive association. First, high consumption of meat containing large amounts of saturated fat and cholesterol is positively associated with obesity, hypertension and dyslipidaemia, all of which factors have been shown to be associated with the risk of MetS ${ }^{(14)}$. Second, red meat intake is related to the storage of $\mathrm{Fe}$, while Fe overload has been documented to be associated with increased risk of insulin resistance ${ }^{(25)}$. Previous studies indicated that individuals with MetS had a significantly higher prevalence of Fe overload than those without $\operatorname{MetS}^{(26)}$. Moreover, higher meat consumption may also be related to inflammation ${ }^{(27)}$, which appears to be involved in pathophysiology of $\operatorname{MetS}^{(28)}$. Some authors have reported that inflammation markers (e.g. IL-6 and C-reactive protein) are associated with an elevated risk of MetS ${ }^{(29,30)}$. Third, processed meat often contains large amounts of salt. An emerging body of evidence has proved that high salt intake is associated with an elevated risk of hypertension $^{(31)}$. Furthermore, the animal food pattern may be closely related to a high intake of alcohol in the present study. In a prospective cohort study of 3833 males and females in Korea, heavy drinking has been reported to be positively associated with MetS and its components ${ }^{(32)}$.

In our analyses, we did not observe a significant association between the high-energy dietary pattern and MetS. Our results are not in agreement with previous studies, which demonstrated a significant relationship between the high-salt and energy pattern and risk of MetS ${ }^{(12)}$. There are several possible explanations for the null association between our high-energy dietary pattern and the risk of MetS. First, some foods (e.g. refined grains, snacks, chocolates and honey) in this pattern have a high glycaemic index, which has been reported to be associated with an increased risk of $\mathrm{MetS}^{(33)}$. Second, high carbohydrate intake may also contribute to excess energy, which has been documented to be related to insulin 
Table 4 General characteristics of the middle-aged adults ( $n$ 1918) across quartile categories of the major dietary pattern scores, city of Linyi, Shandong Province, China, August 2014December 2016

\begin{tabular}{|c|c|c|c|c|c|c|c|c|c|c|c|c|c|c|c|}
\hline & \multicolumn{4}{|c|}{ Traditional Chinese pattern score } & \multirow[b]{3}{*}{$P$ value ${ }^{\star}$} & \multicolumn{4}{|c|}{ Animal food pattern score } & \multirow[b]{3}{*}{$P$ value* } & \multicolumn{4}{|c|}{ High-energy pattern score } & \multirow[b]{3}{*}{$P$ value } \\
\hline & \multicolumn{2}{|c|}{$\begin{array}{c}\text { Q1 } \\
\text { (lowest) } \\
(n \text { 479) }\end{array}$} & \multicolumn{2}{|c|}{$\begin{array}{c}\text { Q4 } \\
\text { (highest) } \\
\text { (n 480) }\end{array}$} & & \multicolumn{2}{|c|}{$\begin{array}{c}\text { Q1 } \\
\text { (lowest) } \\
(n \text { 479) }\end{array}$} & \multicolumn{2}{|c|}{$\begin{array}{c}\text { Q4 } \\
\text { (highest) } \\
\text { (n 479) }\end{array}$} & & \multicolumn{2}{|c|}{$\begin{array}{c}\text { Q1 } \\
\text { (lowest) } \\
\text { (n 480) }\end{array}$} & \multicolumn{2}{|c|}{$\begin{array}{c}\text { Q4 } \\
\text { (highest) } \\
\text { (n 479) }\end{array}$} & \\
\hline & Mean or $n$ & $\%$ or SD & Mean or $n$ & $\%$ or SD & & Mean or $n$ & $\%$ or SD & Mean or $n$ & $\%$ or SD & & Mean or $n$ & $\%$ or SD & Mean or $n$ & $\%$ or SD & \\
\hline Age (years) & $50 \cdot 0$ & 0.2 & 51.9 & 0.3 & $<0.001$ & 51.5 & 0.2 & 49.7 & 0.2 & $<0.001$ & 51.8 & 0.3 & $50 \cdot 3$ & 0.2 & $<0.001$ \\
\hline $\mathrm{BMI}\left(\mathrm{kg} / \mathrm{m}^{2}\right)$ & $25 \cdot 33$ & 2.85 & $24 \cdot 11$ & $2 \cdot 86$ & $<0.01$ & 24.27 & $2 \cdot 81$ & $25 \cdot 10$ & $3 \cdot 12$ & $<0.05$ & 24.39 & $3 \cdot 11$ & 24.93 & 2.96 & 0.225 \\
\hline Waist circumference $(\mathrm{cm})$ & 87.68 & 8.92 & 82.65 & 8.35 & $<0.01$ & 84.05 & $8 \cdot 61$ & 87.05 & 8.24 & $<0.01$ & 84.79 & 9.03 & $85 \cdot 78$ & 8.65 & 0.577 \\
\hline Waist-to-height ratio & 0.89 & 0.06 & 0.86 & 0.08 & $<0.05$ & 0.87 & 0.08 & 0.89 & 0.06 & 0.068 & 0.87 & 0.06 & 0.88 & 0.06 & 0.683 \\
\hline Obesity & 50 & $16 \cdot 7$ & 27 & 8.9 & $<0.01$ & 35 & 11.6 & 55 & $18 \cdot 3$ & $<0.05$ & 36 & $12 \cdot 0$ & 55 & $18 \cdot 3$ & $<0.05$ \\
\hline Hypertension & 110 & $36 \cdot 5$ & 76 & $25 \cdot 2$ & $<0.01$ & 72 & 23.8 & 98 & $32 \cdot 6$ & $<0.05$ & 95 & 31.6 & 105 & 34.9 & 0.387 \\
\hline Metabolic syndrome & 59 & $19 \cdot 6$ & 40 & $13 \cdot 4$ & $<0.05$ & 49 & $16 \cdot 4$ & 75 & $24 \cdot 8$ & $<0.01$ & 61 & $20 \cdot 4$ & 65 & 21.6 & 0.689 \\
\hline Gender & & & & & $<0.001$ & & & & & $<0.05$ & & & & & $<0.001$ \\
\hline Male & 186 & $61 \cdot 8$ & 110 & $36 \cdot 5$ & & 161 & 53.5 & 189 & $62 \cdot 8$ & & 151 & $50 \cdot 2$ & 204 & $67 \cdot 8$ & \\
\hline Female & 115 & $38 \cdot 2$ & 191 & 63.5 & & 140 & $46 \cdot 5$ & 112 & $37 \cdot 3$ & & 150 & 49.8 & 97 & $32 \cdot 2$ & \\
\hline Smoking status & & & & & $<0.05$ & & & & & $<0.001$ & & & & & $<0.05$ \\
\hline Never & 234 & $77 \cdot 7$ & 260 & $86 \cdot 4$ & & 225 & 74.8 & 200 & $66 \cdot 5$ & & 254 & 84.4 & 225 & 74.7 & \\
\hline Current & 49 & $16 \cdot 3$ & 25 & $8 \cdot 3$ & & 48 & $15 \cdot 9$ & 88 & $29 \cdot 2$ & & 43 & $14 \cdot 3$ & 71 & $23 \cdot 6$ & \\
\hline Former & 18 & $6 \cdot 0$ & 16 & $5 \cdot 3$ & & 28 & 9.3 & 13 & $4 \cdot 3$ & & 4 & 1.3 & 5 & 1.7 & \\
\hline Education & & & & & 0.570 & & & & & $<0.001$ & & & & & $<0.001$ \\
\hline$<$ High school & 80 & $26 \cdot 6$ & 70 & $23 \cdot 3$ & & 65 & $21 \cdot 6$ & 60 & $19 \cdot 9$ & & 103 & $34 \cdot 2$ & 49 & $16 \cdot 3$ & \\
\hline High school & 93 & 30.9 & 92 & $30 \cdot 6$ & & 111 & $36 \cdot 9$ & 126 & 41.9 & & 92 & $30 \cdot 6$ & 86 & $28 \cdot 6$ & \\
\hline > High school & 128 & 42.5 & 139 & $46 \cdot 1$ & & 125 & 41.5 & 115 & 38.2 & & 106 & $35 \cdot 2$ & 166 & $55 \cdot 1$ & \\
\hline Monthly income per person & & & & & $<0.05$ & & & & & $<0.05$ & & & & & 0.889 \\
\hline$<2000 \mathrm{RMB}$ & 101 & 33.7 & 76 & $25 \cdot 2$ & & 86 & $28 \cdot 6$ & 61 & $20 \cdot 3$ & & 78 & $25 \cdot 9$ & 82 & $27 \cdot 2$ & \\
\hline 2000-4000 RMB & 121 & $40 \cdot 1$ & 115 & 38.2 & & 121 & $40 \cdot 2$ & 118 & 39.2 & & 126 & 41.9 & 127 & $42 \cdot 2$ & \\
\hline$>4000 \mathrm{RMB}$ & 79 & $26 \cdot 2$ & 110 & $36 \cdot 6$ & & 94 & 31.2 & 122 & 40.5 & & 97 & $32 \cdot 2$ & 92 & 30.6 & \\
\hline Physical activity & & & & & 0.361 & & & & & $<0.05$ & & & & & 0.109 \\
\hline Light & 238 & $79 \cdot 1$ & 237 & $78 \cdot 7$ & & 236 & 78.4 & 254 & 84.4 & & 243 & $80 \cdot 7$ & 262 & 87.0 & \\
\hline Moderate & 56 & $18 \cdot 6$ & 51 & $16 \cdot 9$ & & 49 & $16 \cdot 3$ & 41 & 13.6 & & 46 & $15 \cdot 3$ & 31 & $10 \cdot 3$ & \\
\hline Vigorous & 7 & $2 \cdot 3$ & 13 & 4.4 & & 16 & $5 \cdot 3$ & 6 & $2 \cdot 0$ & & 12 & 4.0 & 8 & 2.7 & \\
\hline Total energy intake $(\mathrm{kJ} / \mathrm{d})$ & 10541 & 962 & 9370 & 816 & $<0.05$ & 9331 & 1174 & 11443 & 1123 & $<0.01$ & 10236 & 1111 & 11145 & 818 & 0.390 \\
\hline Total energy intake $(\mathrm{kcal} / \mathrm{d})$ & $2519 \cdot 3$ & $230 \cdot 0$ & $2239 \cdot 4$ & $195 \cdot 1$ & $<0.05$ & $2230 \cdot 1$ & 280.7 & 2734.9 & 268.4 & $<0.01$ & $2446 \cdot 5$ & 265.5 & 2663.7 & $195 \cdot 6$ & 0.390 \\
\hline
\end{tabular}

Continuous variables are presented as mean and standard deviation; categorical variables as number and percentage.

${ }^{*} P$ values are calculated using ANOVA for continuous variables; the $x^{2}$ test for categorical variables. 
Table 5 Multivariable-adjusted OR and $95 \% \mathrm{Cl}$ for metabolic syndrome in the middle-aged adults $(n 1918)$ across quartile categories of dietary pattern scores, city of Linyi, Shandong Province, China, August 2014-December 2016

\begin{tabular}{|c|c|c|c|c|c|c|}
\hline & \multicolumn{2}{|c|}{ Model 1} & \multicolumn{2}{|c|}{ Model 2} & \multicolumn{2}{|c|}{ Model 3} \\
\hline & OR & $95 \% \mathrm{Cl}$ & OR & $95 \% \mathrm{Cl}$ & OR & $95 \% \mathrm{Cl}$ \\
\hline \multicolumn{7}{|c|}{ Traditional Chinese pattern score } \\
\hline Q1 & 1.00 & Ref. & 1.00 & Ref. & 1.00 & Ref. \\
\hline Q2 & 0.77 & $0.632,1.146$ & 0.89 & $0.655,1.203$ & 0.85 & $0.694,1.207$ \\
\hline Q3 & 0.61 & $0.405,0.836$ & 0.79 & $0.680,1.091$ & 0.90 & $0.701,1.253$ \\
\hline Q4 & 0.50 & $0.364,0.682$ & 0.67 & $0.524,0.857$ & 0.72 & $0.596,0.952$ \\
\hline$P$ value & \multicolumn{2}{|c|}{$<0.001$} & \multicolumn{2}{|c|}{$<0.001$} & \multicolumn{2}{|c|}{$<0.05$} \\
\hline \multicolumn{7}{|c|}{ Animal food pattern score } \\
\hline Q1 & 1.00 & Ref. & 1.00 & Ref. & 1.00 & Ref. \\
\hline Q2 & 1.73 & $1 \cdot 208,2 \cdot 155$ & 1.76 & $1 \cdot 332,2 \cdot 467$ & 1.08 & $0.706,1.454$ \\
\hline Q3 & 1.84 & $1.463,2.715$ & 1.68 & $1.205,2 \cdot 162$ & $1 \cdot 16$ & $1.186,1.907$ \\
\hline Q4 & $2 \cdot 17$ & $1.462,4.063$ & 1.63 & $1.317,2.059$ & $1 \cdot 28$ & $1 \cdot 103,1 \cdot 697$ \\
\hline$P$ value & \multicolumn{2}{|c|}{$<0.001$} & \multicolumn{2}{|c|}{$<0.01$} & \multicolumn{2}{|c|}{$<0.05$} \\
\hline \multicolumn{3}{|c|}{ High-energy pattern score } & & & & \\
\hline Q1 & 1.00 & Ref. & 1.00 & Ref. & 1.00 & Ref. \\
\hline Q2 & 1.07 & $0.806,1.461$ & 0.89 & $0.685,1.307$ & 0.97 & $0.783,1.306$ \\
\hline Q3 & $1 \cdot 104$ & $0.877,1.406$ & 1.01 & $0.775,1.336$ & 1.05 & $0.845,1.804$ \\
\hline Q4 & 1.27 & $1.026,1.537$ & $1 \cdot 13$ & $0.953,1.417$ & 1.09 & $0.825,1.495$ \\
\hline$P$ value & \multicolumn{2}{|c|}{$<0.05$} & \multicolumn{2}{|c|}{0.247} & \multicolumn{2}{|c|}{0.440} \\
\hline
\end{tabular}

Q1, lowest quartile of dietary pattern score; Q4, highest quartile of dietary pattern score; Ref., reference category.

Model 1 adjusted for sex and age; Model 2 further adjusted for education level ( $<$ high school, high school, $>$ high school), physical activity level (light, moderate, heavy), smoking status (never, current, former); Model 3 additionally adjusted for total energy intake.

resistance $^{(34)}$. Nevertheless, in contrast to other studies, the participants in the present study were a group of Chinese adults aged between 45 and 59 years, who consumed less of these foods, especially the high-energy diet. Furthermore, the null association could also be due to reverse causality. In health screening examination, study participants with risk of MetS may have been advised to change their dietary habits and lifestyles, such as limiting the intake of high-energy foods. These possibilities cannot be excluded in the present crosssectional study.

\section{Strengths and limitations}

The present study holds several strengths. First, to our knowledge, it is the first study to report the association between major dietary patterns and the risk of MetS among middle-aged adults in the city of Linyi, Shandong Province, China. It underscores a potential role of dietary modification in the prevention of MetS. Second, faceto-face interviews were used to assess dietary intake using a validated semi-quantitative FFQ, in which most foods consumed in Shandong Province were covered. This tool enabled us to capture more reliable information on usual dietary intake of individuals during the past year. However, several limitations of our study warrant mention. First, due to the cross-sectional study design, a cause-and-effect relationship cannot be established from the findings of the present study. Besides, the limitations of the cross-sectional study design in nutrition research, such as recall and selection bias, warrant caution in interpreting the results. Hence, our findings should be verified in a future prospective study. Second, the principal component analysis require some subjective decisions (e.g. determining the number of factors to be retained, food grouping methods and the labelling of dietary patterns) ${ }^{(35)}$. Third, although some confounding factors have been adjusted for in our analyses, we cannot rule out unmeasured or residual confounding. Finally, our findings may not be generalizable to other age groups because our study population included only middle-aged Chinese.

\section{Conclusions}

Regardless of these limitations, our findings indicate that the traditional Chinese pattern is associated with reduced risk, while the animal food pattern is associated with a greater risk of MetS in a middle-aged Chinese population. Nevertheless, additional prospective studies are needed to confirm the associations between dietary patterns and MetS.

\section{Acknowledgements}

Acknowledgements: The authors thank all participants from the Department of Endocrinology, Linyi People's Hospital, for their assistance and support. They also acknowledge the Medical Center for Physical Examination, Linyi People's Hospital, for its important contributions to collection of data in this study. Financial support: This research received no specific grant from any funding agency in the public, commercial or not-for-profit sectors. Conflict of interest: The authors declare that there is no conflict of interests. Authorship: Z.-Y.W. and Y.-Y.Z. contributed to the study design. J.-J.L., X.-M.Z. and H.-M.F. performed the statistical analysis for the manuscript and drafted the paper. All authors contributed to a critical review of the manuscript during the writing process. 
Ethics of buman subject participation: This study was conducted according to the guidelines laid down in the Declaration of Helsinki and all procedures involving human subjects were approved by the Ethics Committee of Linyi People's Hospital. Written informed consent was obtained from all subjects prior to enrolment.

\section{References}

1. Grundy SM, Brewer HB Jr, Cleeman JI et al. (2004) Definition of metabolic syndrome: report of the National Heart, Lung, and Blood Institute/American Heart Association conference on scientific issues related to definition. Circulation 109, 433-438.

2. Won KB, Chang HJ, Niinuma $\mathrm{H}$ et al. (2015) Inverse association between central obesity and arterial stiffness in Korean subjects with metabolic syndrome: a cross-sectional cohort study. Diabetol Metab Syndr 7, 3.

3. Choi JH, Woo HD, Lee JH et al. (2015) Dietary patterns and risk for metabolic syndrome in Korean women: a crosssectional study. Medicine (Baltimore) 94, e1424.

4. Song QB, Zhao Y, Liu YQ et al. (2015) Sex difference in the prevalence of metabolic syndrome and cardiovascular-related risk factors in urban adults from 33 communities of China: the CHPSNE study. Diabetes Vasc Dis Res 12, 189-198.

5. Ambrosini GL, Huang RC, Mori TA et al. (2010) Dietary patterns and markers for the metabolic syndrome in Australian adolescents. Nutr Metab Cardiovasc Dis 20, 274-283.

6. He Y, Li Y, Lai J et al. (2013) Dietary patterns as compared with physical activity in relation to metabolic syndrome among Chinese adults. Nutr Metab Cardiovasc Dis 23, 920-928.

7. Esmaillzadeh A, Mirmiran P \& Azizi F (2005) Whole-grain consumption and the metabolic syndrome: a favorable association in Tehranian adults. Eur J Clin Nutr 59, 353-362.

8. Lim H, Kim SY, Wang Y et al. (2014) Preservation of a traditional Korean dietary pattern and emergence of a fruit and dairy dietary pattern among adults in South Korea: secular transitions in dietary patterns of a prospective study from 1998 to 2010. Nutr Res 34, 760-770.

9. Zheng PF, Shu L, Si CJ et al. (2016) Dietary patterns and chronic obstructive pulmonary disease: a meta-analysis. COPD 13, 515-522.

10. He DH, Yang M, Zhang RH et al. (2015) Dietary patterns associated metabolic syndrome in Chinese adults. Biomed Environ Sci 28, 370-373.

11. Gadgil MD, Anderson CA, Kandula NR et al. (2015) Dietary patterns are associated with metabolic risk factors in South Asians living in the United States. J Nutr 145, 1211-1217.

12. Xu SH, Qiao N, Huang JJ et al. (2016) Gender differences in dietary patterns and their association with the prevalence of metabolic syndrome among Chinese: a cross-sectional study. Nutrients $\mathbf{8}, 180$.

13. Yakub M, Iqbal MP \& Iqbal R (2010) Dietary patterns are associated with hyperhomocysteinemia in an urban Pakistani population. J Nutr 140, 1261-1266.

14. Shu L, Zheng PF, Zhang XY et al. (2015) Association between dietary patterns and the indicators of obesity among Chinese: a cross-sectional study. Nutrients 7, 7995-8009.

15. Yu XL, Shu L, Shen XM et al. (2017) Gender difference on the relationship between hyperuricemia and nonalcoholic fatty liver disease among Chinese: an observational study. Medicine (Baltimore) 96, e8164.

16. Alberti KG, Eckel RH, Grundy SM et al. (2009) Harmonizing the metabolic syndrome: a joint interim statement of the International Diabetes Federation Task Force on Epidemiology and Prevention; National Heart, Lung, and Blood Institute; American
Heart Association; World Heart Federation; International Atherosclerosis Society; and International Association for the Study of Obesity. Circulation 120, 1640-1645.

17. Baik I, Lee M, Jun NR et al. (2013) A healthy dietary pattern consisting of a variety of food choices is inversely associated with the development of metabolic syndrome. Nutr Res Pract 7, 233-241.

18. Musso G, Gambino R, De Michieli F et al. (2003) Dietary habits and their relations to insulin resistance and postprandial lipemia in nonalcoholic steatohepatitis. Hepatology 37, 909-916.

19. McKeown NM, Meigs JB, Liu S et al. (2004) Carbohydrate nutrition, insulin resistance, and the prevalence of the metabolic syndrome in the Framingham Offspring Cohort. Diabetes Care 27, 538-546.

20. Williams DE, Prevost AT, Whichelow MJ et al. (2000) A cross-sectional study of dietary patterns with glucose intolerance and other features of the metabolic syndrome. $\mathrm{BrJ}$ Nutr 83, 257-266.

21. Esmaillzadeh A, Kimiagar M, Mehrabi Y et al. (2006) Fruit and vegetable intakes, C-reactive protein, and the metabolic syndrome. Am J Clin Nutr 84, 1489-1497.

22. Kim J \& Choi YH (2016) Physical activity, dietary vitamin C, and metabolic syndrome in the Korean adults: the Korea National Health and Nutrition Examination Survey 2008 to 2012. Public Health 135, 30-37.

23. Hosseini-Esfahani F, Mirmiran P, Daneshpour MS et al. (2014) Western dietary pattern interaction with APOC3 polymorphism in the risk of metabolic syndrome: Tehran Lipid and Glucose Study. J Nutrigenet Nutrigenomics 7, 105-117.

24. Woo HD, Shin A \& Kim J (2014) Dietary patterns of Korean adults and the prevalence of metabolic syndrome: a crosssectional study. PLoS One $\mathbf{9}$, e111593.

25. Sun L, Franco OH, Hu FB et al. (2008) Ferritin concentrations, metabolic syndrome, and type 2 diabetes in middleaged and elderly Chinese. J Clin Endocrinol Metab 93, 4690-4696.

26. Bozzini C, Girelli D, Olivieri O et al. (2005) Prevalence of body iron excess in the metabolic syndrome. Diabetes Care 28, 2061-2063.

27. Azadbakht L \& Esmaillzadeh A (2009) Red meat intake is associated with metabolic syndrome and the plasma C-reactive protein concentration in women. $J$ Nutr 139, 335-339.

28. Welty FK, Alfaddagh A \& Elajami TK (2016) Targeting inflammation in metabolic syndrome. Transl Res 167, 257-280.

29. Yan YZ, Ma RL, Ding YS et al. (2015) Association of inflammation with metabolic syndrome among low-income rural Kazakh and Uyghur adults in far western China. Mediators Inflamm 2015, 706768.

30. Wickramatilake CM, Mohideen MR \& Pathirana C (2015) Association of metabolic syndrome with testosterone and inflammation in men. Ann Endocrinol (Paris) 76, 260-263.

31. Brown IJ, Tzoulaki I, Candeias V et al. (2009) Salt intakes around the world: implications for public health. Int $J$ Epidemiol 38, 791-813.

32. Baik I \& Shin C (2008) Prospective study of alcohol consumption and metabolic syndrome. Am J Clin Nutr 87, $1455-1463$.

33. Juanola-Falgarona M, Salas-Salvado J, Buil-Cosiales $\mathrm{P}$ et al. (2015) Dietary glycemic index and glycemic load are positively associated with risk of developing metabolic syndrome in middle-aged and elderly adults. J Am Geriatr SOC 63, 1991-2000.

34. Feng R, Du S, Chen Y et al. (2015) High carbohydrate intake from starchy foods is positively associated with metabolic disorders: a cohort study from a Chinese population. Sci Rep 5, 16919

35. DiBello JR, McGarvey ST, Kraft P et al. (2009) Dietary patterns are associated with metabolic syndrome in adult Samoans. J Nutr 139, 1933-1943. 